\title{
Otimização das condições de moagem em moinho planetário e efeito da distribuição do tamanho de partículas na sinterização de um vidro do sistema $\mathrm{Li}_{2} \mathrm{O} \cdot \mathrm{Al}_{2} \mathrm{O}_{3} \cdot \mathrm{SiO}_{2}$ (LAS)
}

\author{
Optimization of milling condition in a planetary mill \\ and effect of particle size distribution on sintering \\ of a $\mathrm{Li}_{2} \mathrm{O} \cdot \mathrm{Al}_{2} \mathrm{O}_{3} \cdot \mathrm{SiO}_{2}$ (LAS) glass
}

\author{
Viviane Oliveira Soares ${ }^{1}$, Gustavo Rocha de Paula ${ }^{2}$, \\ Mariana de Oliveira Carlos Villas Boas ${ }^{3}$, Roney Peterson Pereira ${ }^{1}$
}

\footnotetext{
${ }^{1}$ Departamento de Ciências - Universidade Estadual de Maringá - CEP: 87360-000, Goioerê, PR, Brasil.

${ }^{2}$ Infibra - Rod. Anhanguera Km 186 - CEP: 13610-970, Leme, SP, Brasil.

${ }^{3}$ Associação de Escolas Reunidas - R. Padre Nestor C. Maranhão, 40 - CEP: 13660-000, Porto Ferreira, SP, Brasil.

e-mail: vosoares@uem.br, grpaula@hotmail.com, marianaoc@yahoo.com.br, roney_peterson@hotmail.com
}

\begin{abstract}
RESUMO
A otimização das condições de moagem é importante para a sinterização de vidros, uma vez que permite a obtenção de pós em curtos intervalos de tempo, com menor tendência à cristalização superficial e consequente maior sinterabilidade. Neste trabalho investigou-se as condições de moagem de alta energia para obtenção de partículas vítreas com diâmetro médio abaixo de $5 \mu \mathrm{m}$, utilizando-se um moinho planetário. Variou-se o diâmetro dos meios de moagem, com o objetivo de obter partículas finas no menor tempo possível, também foram comparadas a moagem a seco e a úmido. Foi realizada a sinterização de um vidro do sistema $\mathrm{Li}_{2} \mathrm{O} \cdot \mathrm{Al}_{2} \mathrm{O}_{3} \cdot \mathrm{SiO}_{2}$ (LAS), a partir dos pós obtidos sob as condições ótimas de moagem. Este vidro foi utilizado por apresentar elevada cristalização superficial. As moagens realizadas com tempos de 60 min e 90 min apresentaram um diâmetro médio de partículas de cerca de $5 \mu \mathrm{m}$ e $3 \mu \mathrm{m}$ respectivamente, após a sinterização as vitrocerâmicas obtidas apresentaram fração de poros abaixo de 5\%. Moagens com maiores tempos (200 minutos) levaram a pós com baixíssimo diâmetro médio $(0,70-0,80 \mu \mathrm{m})$, contudo estes pós não deram bons resultados sob o ponto de vista da sinterização. A moagem a úmido utilizando álcool isopropílico mostrou-se extremamente danosa para a sinterização do vidro LAS, levando a uma vitrocerâmica com fração de poros de $20 \pm 1 \%$. Nossos estudos demonstraram que, para favorecer a sinterização de pós vítreos que apresentem alta tendência à cristalização superficial, é recomendável a utilização da moagem de alta energia a seco e por tempos de moagem inferiores a 90min.
\end{abstract}

Palavras-chave: moagem de alta energia, tamanho de partícula, vidro, sinterização.

\section{ABSTRACT}

The optimization of the milling conditions is important for the sintering of glasses, since it allows the obtaining of powders in short intervals of time, with less tendency to the superficial crystallization and consequent greater sinterability. In this work, the high-energy milling conditions were investigated to obtain vitreous powders with an average particle size under $5 \mu \mathrm{m}$, using a planetary mill. The diameter of the milling media was varied in order to obtain fine particles in the shortest possible time, also the dry and wet milling were compared. The sintering of a glass from the $\mathrm{Li}_{2} \mathrm{O} \cdot \mathrm{Al}_{2} \mathrm{O}_{3} \cdot \mathrm{SiO}_{2}$ (LAS) system was performed, using the powders obtained under the optimum milling conditions. This glass was used due its high surface crystallization tendency. The milling time of $60 \mathrm{~min}$ and 90 min showed an average particle size of about $5 \mu \mathrm{m}$ and $3 \mu \mathrm{m}$, respectively. The obtained glass-ceramics showed pore fraction below 5\%. Milling with longer times ( 200 minutes) led to very low average particle size $(0.70-0.80 \mu \mathrm{m})$, however these powders did not presented high densification. Wet milling using isopropyl alcohol was extremely damaging for LAS sintering, leading to a glass-ceramic with a pore fraction of $20 \pm 1 \%$. We demonstrated that to favor the sintering of vitreous powders, which have a high tendency to surface crystallization, it is recommended to use dry high-energy milling 
and milling times up to 90 minutes.

Keywords: high impact milling, particle size, glass, sintering.

\section{INTRODUÇÃO}

A sinterização de vidros é um método alternativo proposto em 1965 por Sack para a preparação de vitrocerâmicas [1]. O processo consiste na fabricação de um vidro, com determinada composição, que é moído resultando em um pó que é conformado e sinterizado. Geralmente durante o processo de sinterização, a cristalização da superfície das partículas vítreas ocorre simultaneamente. Com isto, a viscosidade do sistema aumenta, impedindo a densificação completa por fluxo viscoso e levando a um corpo poroso e parcialmente cristalizado. Isto acontece devido à alta área superficial disponível para a nucleação e ao elevado número de sítios de nucleação por unidade de área $\left(\mathrm{N}_{\mathrm{s}}\right)$ presente na superfície das partículas [2].

A grande maioria dos pós vítreos têm tendência a cristalizar na superfície quando tratados termicamente [3, 4]. Müller [3] verificou que a cristalização superficial está relacionada a qualidade da superfície, ou seja, a presença de riscos, trincas, partículas contaminantes, atmosfera circundante e outros. Os defeitos criados na superfície das partículas durante o processo de moagem podem atuar como sítios de nucleação. Desta forma, um processo de moagem que leve a um dano severo irá favorecer a cristalização precoce da superfície das partículas impedindo a sinterização via fluxo viscoso. Estudos anteriores mostraram que a utilização de moinhos de alta energia levam a partículas de tamanho pequeno em curtos intervalos de tempo, resultando em um menor $\mathrm{N}_{\mathrm{s}}[5]$.

Soares et al. [6] demonstraram a importância de se obter pós vítreos com baixo valor de $\mathrm{N}_{\mathrm{s}}$ a fim de maximizar a sinterização. Eles compararam a sinterização não-isotérmica de dois pós vítreos com distribuição de tamanho de partículas muito similares, obtidos por processos de moagem diferentes (convencional e de alta energia). Foi verificado que o pó obtido por moagem de alta energia apresentou maior densificação, devido ao seu menor $\mathrm{N}_{\mathrm{s}}$ (fração de poros < $2 \%$ ). Por outro lado, para o pó obtido via moagem tradicional a cristalização completa da superfície das partículas ocorria antes do compacto atingir sua máxima densificação, levando a uma vitrocerâmica com fração de poros superior a $10 \%$, isto foi atribuído ao elevado valor de $\mathrm{N}_{\mathrm{s}}$ deste pó.

A eficiência da moagem de alta energia (ex.: moinho planetário) se deve a dinâmica dos meios de moagem dentro do jarro, esta dinâmica é diferente daquela da moagem de menor energia (ex.: moinho de jarros tradicional) [7]. No moinho de jarros tradicional ocorre a moagem por efeito cascata dos meios de moagem que rolam uns sobre os outros. Neste caso, a moagem ocorre predominantemente por atrito, sendo introduzido um maior número de defeitos na superfície das partículas. Já no moinho planetário, o jarro apresenta movimento de translação e rotação simultaneamente, sendo que os meios de moagem são arremessados uns contra os outros e contra a parede do jarro, realizando a moagem por impacto e com muito maior energia que no moinho de jarros. Isto resulta em tempos curtos de moagem e em partículas com baixo valor de $\mathrm{N}_{\mathrm{s}}$ [8]. Embora a moagem de alta energia seja amplamente utilizada para obtenção de partículas dos mais diversos materiais e também para a síntese de pós, incluindo nanopartículas [9, 10,11], em nossas buscas não foram encontrados trabalhos que apresentem estudos da otimização dos parâmetros de moagem de alta energia para vidros, em especial a otimização da redução do tempo de moagem.

Neste trabalho investigou-se as condições de moagem para obtenção de partículas vítreas com diâmetro médio abaixo de $5 \mu \mathrm{m}$ utilizando um moinho planetário. O principal objetivo foi a obtenção de partículas finas em curtos tempos de moagem, minimizando o dano na superfície das partículas e favorecendo assim a sinterização por fluxo viscoso. Também foi avaliada a sinterização de um vidro do sistema LAS, considerando diferentes distribuições de tamanhos de partículas. Este vidro foi escolhido por apresentar elevada cristalização superficial.

\section{MATERIAIS E MÉTODOS}

A determinação dos parâmetros de moagem foi realizada utilizando-se o vidro comercial de composição típica $15 \mathrm{Na}_{2} \mathrm{O} .10 \mathrm{CaO} .75 \mathrm{SiO}_{2}$, também conhecido como vidro de janela. O vidro foi previamente moído em um almofariz até a obtenção de partículas passantes em peneira malha 10 mesh e retidas em peneira malha 18 mesh (entre 2 - $1 \mathrm{~mm}$ ). Em seguida estas partículas foram submetidas ao processo de moagem à seco em um moinho planetário de alta energia Pulverisete 5 (Fritsh). Utilizou-se um jarro de ágata de $250 \mathrm{ml}$ e bolas de ágata de 10, 20 e $30 \mathrm{~mm}$ de diâmetro.

Com o intuito de determinar as condições de moagem que levassem a partículas finas em um menor 
tempo possível de moagem, foi montada uma planilha com todas as combinações possíveis de moagens empregando-se bolas de ágata de 10, 20 e $30 \mathrm{~mm}$, com intervalo de tempo variando de $10 \mathrm{em} 10$ minutos e para um tempo total de moagem de 30 e 60 minutos. O número de bolas de cada tamanho, adicionado ao jarro antes das moagens, seguiu as orientações do fabricante do equipamento. Foram empregadas 6 bolas de 30 $\mathrm{mm}, 15$ bolas de $20 \mathrm{~mm}$ ou 50 bolas de $10 \mathrm{~mm}$. O volume inicial de partículas de vidro utilizado em cada moagem foi de $30 \mathrm{ml}$, quantidade mínima sugerida pelo fabricante para jarros de $250 \mathrm{ml}$. Nas moagens com bolas de $30 \mathrm{~mm}$ ou $20 \mathrm{~mm}$ utilizou-se a uma rotação de $450 \mathrm{rpm}$ e nas moagens com bolas de $10 \mathrm{~mm}$ utilizouse uma rotação de $550 \mathrm{rpm}$.

Os pós vítreos obtidos foram submetidos a um analisador de distribuição de tamanho de partículas por dispersão a laser (Horiba - LA930).

Após a realização das moagens e a determinação do diâmetro médio das partículas, foram selecionadas as duas melhores condições, para moagens por 30 e 60 minutos, que levavam aos menores tamanhos médios de partículas. Foram realizadas também moagens por 90 e 200 minutos, nestas moagens partiu-se do pó obtido da condição de moagem por 60 minutos com 15 bolas de $20 \mathrm{~mm}$. Portanto, para totalizar 90 minutos de moagem este pó foi moído por mais 30 minutos, onde variou-se o tamanho de bolas (20 mm e $10 \mathrm{~mm}$ ) para todas as combinações possíveis considerando um intervalo de tempo de $10 \mathrm{em} 10$ minutos onde era feita a troca dos meios de moagem, estas condições foram: 30 minutos com bolas de $20 \mathrm{~mm}$; 30 minutos com bolas de $10 \mathrm{~mm}$; 10 minutos com bolas de $20 \mathrm{~mm}$ seguido de 20 minutos com bolas de $10 \mathrm{~mm}$; 20 minutos com bolas de $20 \mathrm{~mm}$ seguidos de 10 minutos com bolas de $10 \mathrm{~mm}$. Para as moagens de 200 minutos, partiu-se da melhor condição obtida na moagem de 90 minutos (70 minutos com bolas de $20 \mathrm{~mm}$ seguidos de 20 minutos com bolas de $10 \mathrm{~mm}$ ), em seguida empregou-se somente bolas de $10 \mathrm{~mm}$ por mais 110 minutos.

Para avaliar o efeito da moagem em meio úmido, utilizou-se álcool isopropílico ou água na razão de 0,75 do volume inicial das partículas de vidro pelo volume de líquido, ou seja, para $30 \mathrm{ml}$ de partículas de vidro utilizou-se $40 \mathrm{ml}$ de álcool isopropílico ou água. As condições de moagem a úmido seguiram os parâmetros de otimização determinados na moagem a seco, como o diâmetro dos meios de moagem e o tempo de moagem.

Foram realizadas moagens em moinho de bolas convencional, em meio úmido, com uma razão de vidro/álcool isopropílico de 0,75 . A distribuição de tamanho de partículas foi medida para diferentes tempos de moagem. Isto foi feito com o intuito de comparar o tempo de moagem no processo de moagem convencional com aquele do processo de moagem de alta energia.

Para avaliar a sinterização dos pós vítreos obtidos a partir das condições otimizadas de moagem em moinho planetário de alta energia, foi utilizado um vidro do sistema $\mathrm{Li}_{2} \mathrm{O}_{2} \cdot \mathrm{Al}_{2} \mathrm{O}_{3} \cdot \mathrm{SiO}_{2}(\mathrm{LAS})$ de composição nominal (\%mol): $66 \mathrm{SiO}_{2} ; 15,3 \mathrm{Al}_{2} \mathrm{O}_{3} ; 8,26 \mathrm{Li}_{2} \mathrm{O} ; 1,87 \mathrm{~B}_{2} \mathrm{O}_{3} ; 1,37 \mathrm{P}_{2} \mathrm{O}_{5} ; 1,61 \mathrm{MgO} ; 1,16 \mathrm{CaO} ; 0,8 \mathrm{CaO} ; 2,1$ $\mathrm{Na}_{2} \mathrm{O} ; 0,69 \mathrm{~K}_{2} \mathrm{O} ; 0,52 \mathrm{SnO}_{2} ; 0,33 \mathrm{As}_{2} \mathrm{O}_{3}$. Este vidro foi utilizado por apresentar cristalização superficial elevada, sendo importante nestes casos a obtenção de pós finos em curtos intervalos de tempo, visando minimizar o valor de $\mathrm{N}_{\mathrm{s}}$ e assim favorecer a sinterização por fluxo viscoso.

Os pós obtidos foram prensados em molde de aço via prensagem uniaxial a $65 \mathrm{MPa}$ por $15 \mathrm{~s}$, foi utilizado $0,1 \%$ em peso de ácido oleico como aditivo. Após a prensagem, as pastilhas foram tratadas a $400^{\circ} \mathrm{C}$ por 2 horas para eliminar o ácido oleico previamente adicionado ao pó. Em seguida, as amostras foram sinterizadas em um forno elétrico tubular a $1100^{\circ} \mathrm{C}$, usando uma taxa de aquecimento de $30^{\circ} \mathrm{C} / \mathrm{min}$. Durante a sinterização não foi usado tempo de patamar na máxima temperatura de sinterização, assim que a temperatura de $1100^{\circ} \mathrm{C}$ foi atingida a amostra foi resfriada a uma taxa aproximada de $15^{\circ} \mathrm{C} / \mathrm{min}$, o que corresponde a taxa de resfriamento livre do forno elétrico utilizado. Após a sinterização, as amostras foram desbastadas em lixas de $\mathrm{SiC}$ e polidas em uma suspensão de óxido de cério. A fração de poros residuais foi determinada com o auxílio da microscopia óptica, utilizando um microscópio óptico Leica DM-RX acoplado com um software analisador de imagem (Image-J). O aumento utilizado foi de 100 vezes e para cada amostra foram analisadas 10 imagens.

\section{RESULTADOS}

\subsection{Otimização do processo de moagem em moinho planetário de alta energia}

Para determinar as melhores condições de moagem, no moinho planetário, foram construídos diagramas ternários com as combinações de moagens realizadas para o vidro de janela, empregando-se bolas de 30, 20 e $10 \mathrm{~mm}$ de diâmetro. As Figuras 1 e 2 mostram o tamanho médio de partícula obtido para as moagens feitas 
por 30 min e 60 min respectivamente.

As moagens realizadas somente com bolas de mesmo tamanho são identificadas nos vértices desses diagramas com as letras A, B e C. A letra A refere-se às moagens realizadas somente com bolas de $30 \mathrm{~mm}$, a letra $\mathrm{B}$ às realizadas com bolas de $20 \mathrm{~mm}$, e a letra $\mathrm{C}$ às moagens com bolas de $10 \mathrm{~mm}$. Os pontos localizados nas arestas são referentes às moagens com bolas de dois tamanhos e os pontos no interior dos diagramas às moagens com bolas de três tamanhos distintos. Por exemplo, o ponto $\mathrm{P}$ identificado na Figura 1 é referente a uma moagem de 10 minutos com bolas de $30 \mathrm{~mm}$ (A) e 20 minutos com bolas de $10 \mathrm{~mm}$ (C), totalizando 30 minutos de moagem. Já o ponto U da Figura 2 refere-se a uma moagem de 20 minutos com bolas de $30 \mathrm{~mm}$ (A), 30 minutos com bolas de $20 \mathrm{~mm}$ (B) e 10 minutos com bolas de $10 \mathrm{~mm}$ (C), para um tempo total de moagem de 60 minutos.

Nota-se pela Figura 1 que o uso de apenas bolas de $20 \mathrm{~mm}$ (B) levou ao menor diâmetro médio de partículas $(15,02 \mu \mathrm{m})$, para um tempo total de moagem de 30 minutos. Com base no diâmetro inicial do pó (entre 1-2 mm), pode-se afirmar que houve um rápido decréscimo no tamanho médio das partículas do vidro, o que é um indicativo da alta energia associada às moagens em moinho planetário. Já pela Figura 2, pode ser observado que o uso de bolas de $20 \mathrm{~mm}$ novamente levou ao menor diâmetro médio de partículas nos primeiros 60 minutos de moagem $(4,88 \mu \mathrm{m})$.
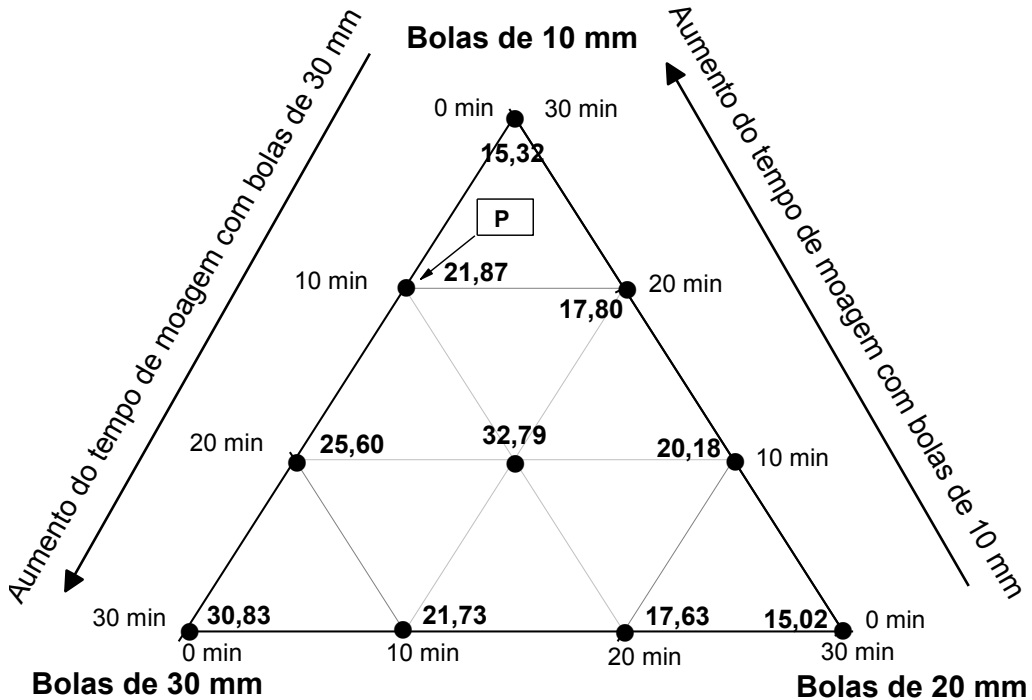

Aumento do tempo de moagem com bolas de $20 \mathrm{~mm}$

Figura 1: Diâmetro médio das partículas de vidro de janelados pós obtidos de moagens com bolas de $30 \mathrm{~mm}$ (A), $20 \mathrm{~mm}$ (B) e $10 \mathrm{~mm}$ (C) com um tempo total de moagem de 30 minutos, apresentado em um diagrama ternário.

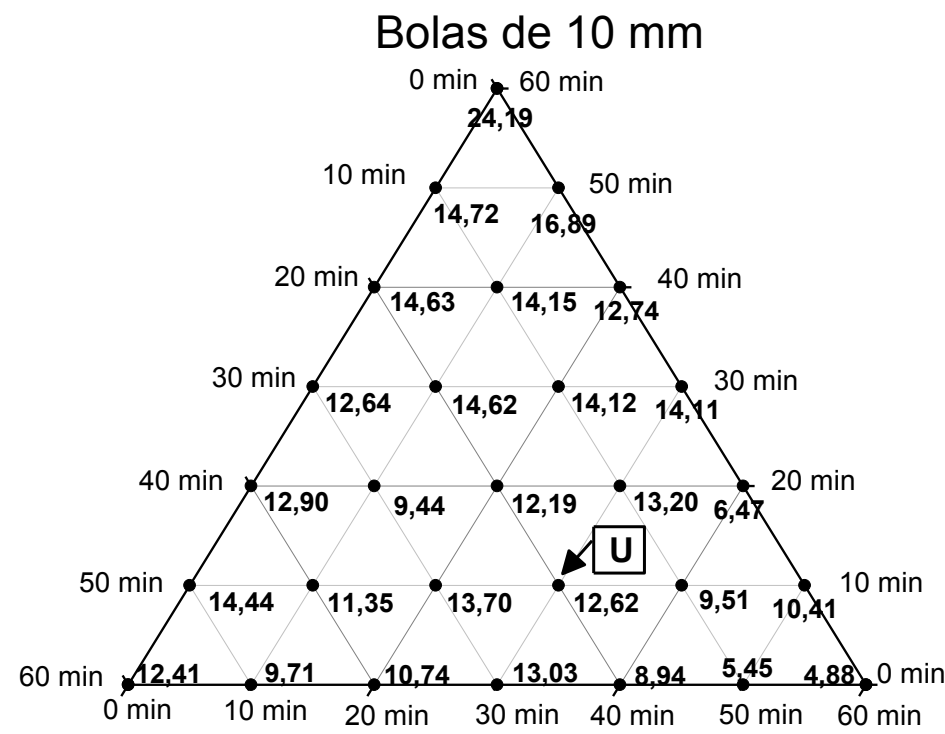


Figura 2: Diâmetro médio das partículas de vidro dos pós obtidos de moagens com bolas de $30 \mathrm{~mm}$ (A), $20 \mathrm{~mm}$ (B) e 10 $\mathrm{mm}(\mathrm{C})$, com um tempo total de moagem de 60 minutos, apresentado em um diagrama ternário.

Para as moagens por 90 minutos, partiu-se da melhor condição obtida na moagem de 60 minutos (somente com bolas de $20 \mathrm{~mm}$ ). Foram testadas, portanto, todas as combinações possíveis com esferas de 20 $\mathrm{mm}$ e $10 \mathrm{~mm}$, com intervalos de tempo de $10 \mathrm{em} 10$ minutos totalizando mais 30 minutos de moagem. A Tabela 1 mostra todas as condições de moagem totalizando um tempo de 90 min e os respectivos diâmetros médios de partículas alcançados. A melhor condição de moagem que levou ao menor tamanho médio de partículas em 90 minutos foi: 70 minutos de moagem com bolas de $20 \mathrm{~mm}$ e os 20 minutos restantes com bolas de $10 \mathrm{~mm}$. O diâmetro médio de partículas obtido nesta condição foi de 3,27 $\mu \mathrm{m}$.

Para as moagens de 200 minutos, partiu-se da melhor condição obtida na moagem de 90 minutos, empregou-se somente bolas de $10 \mathrm{~mm}$ por mais 110 minutos. O diâmetro médio de partícula alcançado para este pó foi de $0,9 \mu \mathrm{m}$.

Tabela 1: Diâmetro médio das partículas de vidro obtidas de moagens com bolas de $20 \mathrm{~mm}$ e $10 \mathrm{~mm}$ com um tempo total de moagem de 90 minutos.

\begin{tabular}{|c|c|c|}
\hline $\begin{array}{c}\text { TEMPO DE MOAGEM COM BOLAS } \\
\text { DE } 20 \mathrm{~mm} \text { (MINUTOS) }\end{array}$ & $\begin{array}{c}\text { TEMPO DE MOAGEM COM BOLAS } \\
\text { DE } 10 \mathrm{~mm} \text { (MINUTOS) }\end{array}$ & $\begin{array}{l}\text { DIÂMETRO MÉDIO DE PARTÍCULAS } \\
\qquad(\mu \mathrm{m})\end{array}$ \\
\hline 60 & 30 & 4,90 \\
\hline 70 & 20 & 3,27 \\
\hline 80 & 10 & 3,72 \\
\hline 90 & 0 & 3,43 \\
\hline
\end{tabular}

A Tabela 2 mostra as condições de moagem que levaram a um menor valor de diâmetro médio de partículas, para os tempos de moagem de $30 \mathrm{~min}, 60 \mathrm{~min}, 90 \mathrm{~min}$ e $200 \mathrm{~min}$.

Tabela 2: Condições de moagem a seco que levam ao menor diâmetro médio de partícula em cada tempo de moagem adotado.

\begin{tabular}{c|c|c|c|c}
\hline \multicolumn{3}{c|}{ TEMPO DE MOAGEM (MIN) } & \multirow{2}{*}{ D MÉDIO $(\boldsymbol{\mu m})$} \\
\hline TOTAL & C/ BOLAS 30 $\mathbf{~ m m}$ & C/ BOLAS 20 $\mathbf{~ m m}$ & C/ BOLAS 10 $\mathbf{~ m m}$ & \\
\hline 30 & 0 & 30 & 0 & 15,02 \\
\hline 60 & 0 & 60 & 0 & 4,88 \\
\hline 90 & 0 & 70 & 20 & 3,27 \\
\hline 200 & 0 & 70 & 130 & 0,9 \\
\hline
\end{tabular}

A fim de avaliar o efeito da moagem a úmido, foram realizadas moagens em álcool isopropílico. A Figura 3 compara o diâmetro médio das partículas obtidas com a moagem em álcool e a moagem a seco. A moagem em meio líquido foi eficiente para a diminuição do diâmetro médio de partículas apenas nos trinta primeiros minutos de moagem. A partir daí os pós apresentavam aproximadamente o mesmo diâmetro médio de partículas independentemente do tipo de moagem. A Figura 3 mostra ainda que para tempos de moagem superiores a 140 minutos, a redução do diâmetro médio de partículas não foi significativa. Existe um limite inferior de diâmetro médio de partículas atingido, que neste caso é em torno de $0,7 \mu \mathrm{m}$.

Como pode ser visto na Figura 4, a moagem de vidros em moinho de jarros convencional também leva ao mesmo valor limite de diâmetro médio de partículas $(0,7 \mu \mathrm{m})$. Porém, o tempo necessário para atingir este 
limite é de 190 horas, sendo que para a obtenção de partículas de tamanho similar em moinho planetário são necessários apenas 140 minutos (Figura 3).

Assim, tem-se que utilizando um moinho planetário de alta energia, mesmo empregando-se moagem a úmido ou a seco, não foi possível obter partículas de vidro de janela com diâmetro médio inferior a 0,7 $\mu \mathrm{m}$. No entanto, a moagem de alta energia, comparada à moagem em moinho de jarros convencional, foi determinante para o decréscimo do tempo de moagem, como pode ser visto nas Figuras 3 e 4 . Fica evidente a eficácia da moagem de alta energia para a obtenção de pós vítreos em curtos intervalos de tempo, quando comparada à moagem convencional.

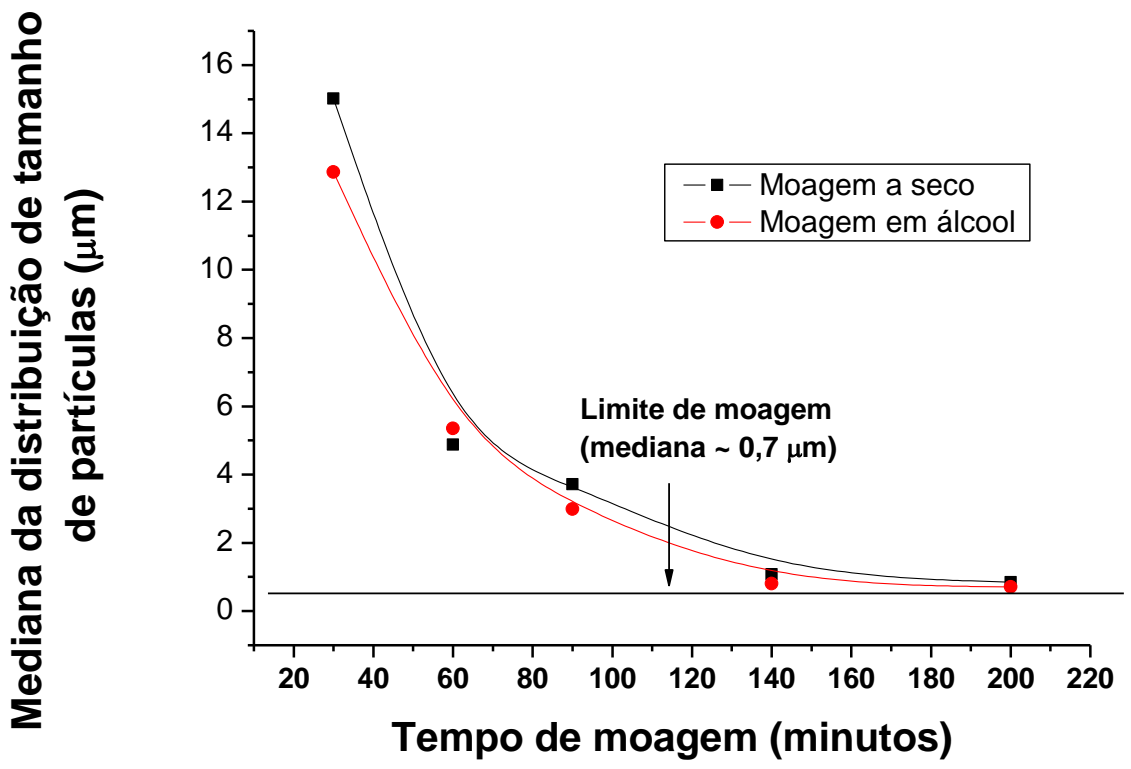

Figura 3: Variação da mediana da distribuição de tamanho de partículas em função do tempo de moagem em moinho planetário.

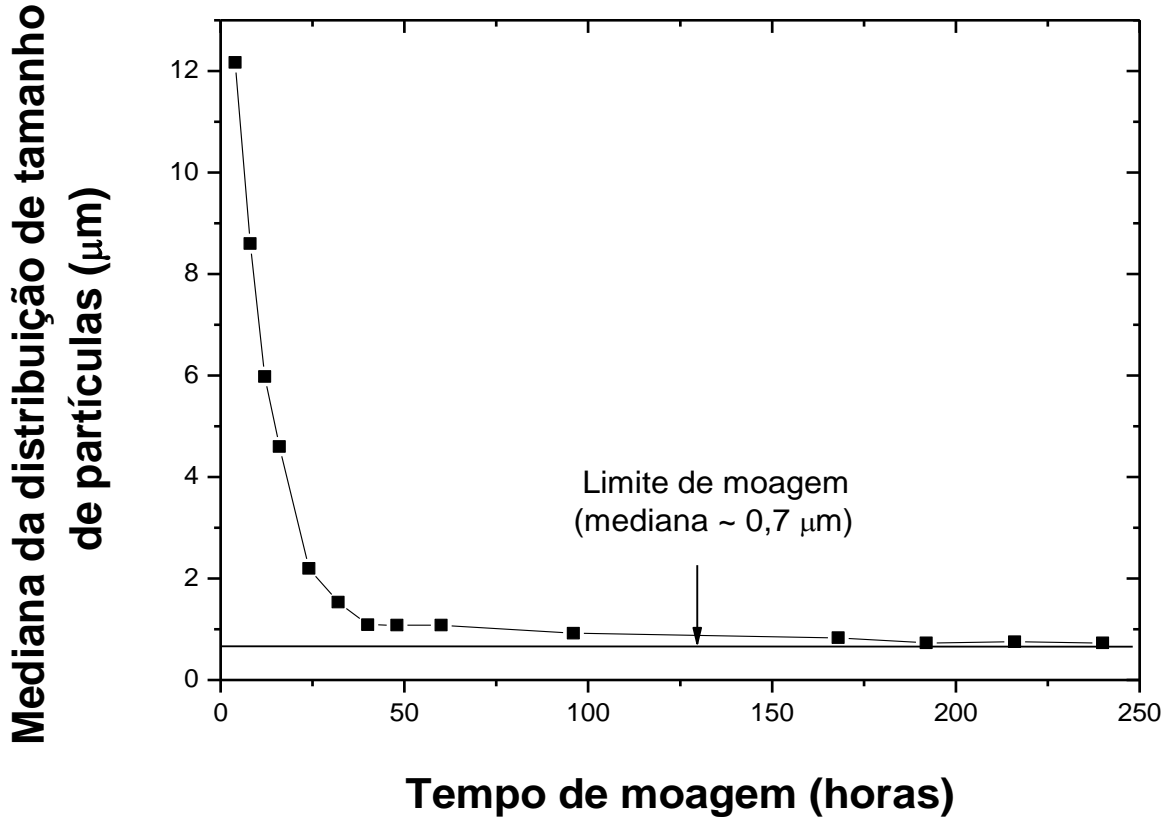


Figura 4: Variação da mediana da distribuição de tamanho de partículas em função do tempo de moagem (vidro de janela moído em moinho de jarros com material de partida entre 2-1 mm moídos em álcool isopropílico).

\subsection{Sinterização de um vidro do sistema LAS}

A Figura 5 mostra a distribuição de tamanho de partículas do vidro LAS moído nas mesmas condições que foram otimizadas para o vidro de janela. Observa-se que com o aumento do tempo de moagem foram obtidas curvas de distribuição de tamanho de partículas mais estreitas, isso é uma consequência da moagem ocorrer preferencialmente sobre as partículas de maior tamanho.

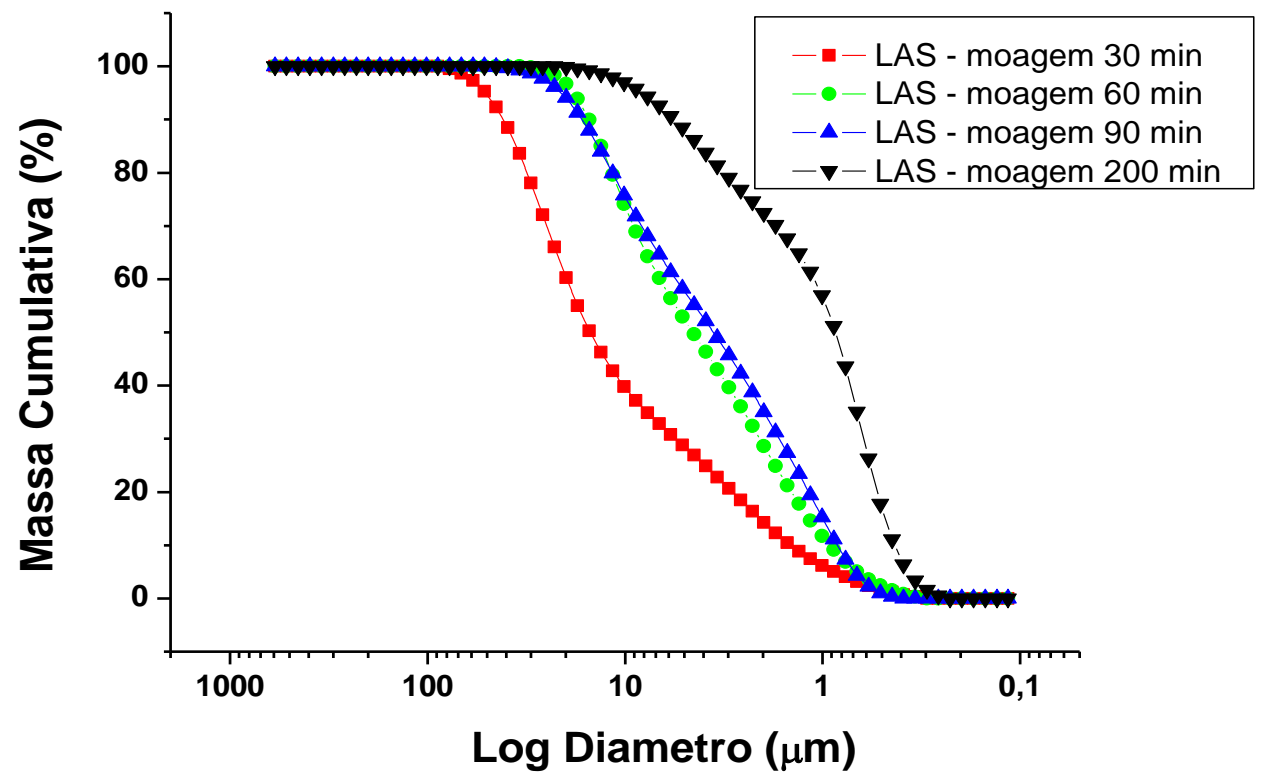

Figura 5: Distribuição de tamanho de partículas do vidro LAS moído em moinho planetário em diferentes condições.

A Figura 6 mostra comparativamente as curvas de distribuição de tamanho de partículas dos pós do vidro LAS e do vidro de janela, moídos nas mesmas condições. Nota-se que essas curvas estão bem próximas umas das outras, o que significa que o vidro de janela foi um bom padrão para o estudo de moagem.

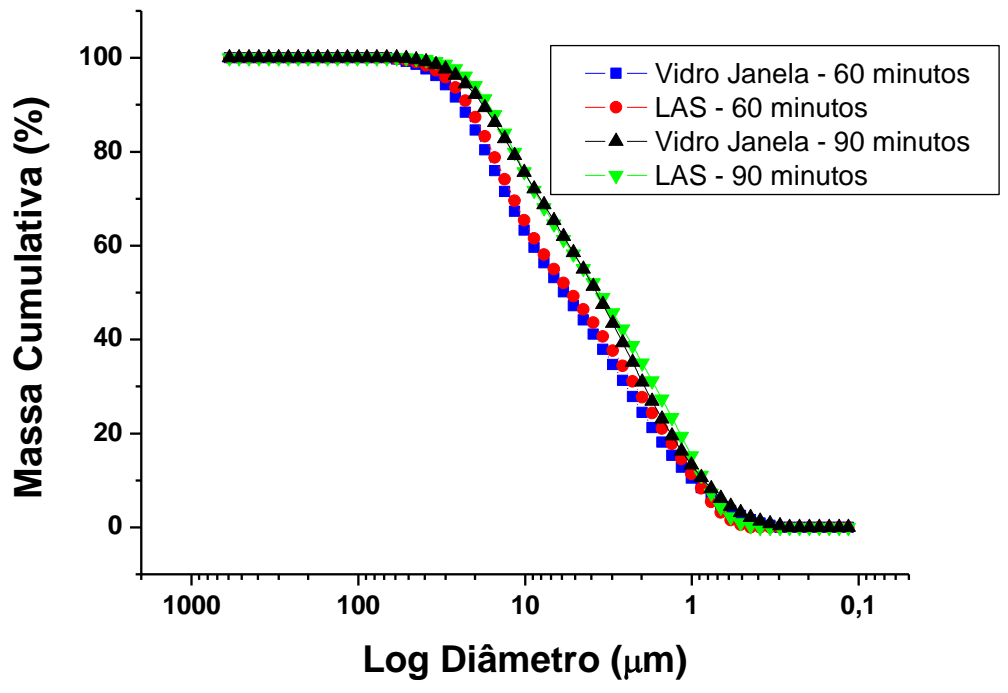


Figura 6: Distribuição de tamanho de partículas do vidro LAS comparada a do vidro de janela.

Para avaliar o efeito da moagem a úmido na sinterização do vidro LAS, foi realizada a moagem por 200 min utilizando-se água ou álcool isopropílico. A Figura 7 mostra as curvas de distribuição de tamanho de partículas do vidro LAS moído na presença de água, álcool isopropílico e a seco. O pó obtido através da moagem em meio líquido por $200 \mathrm{~min}$, apresentou tamanho médio de partículas ligeiramente menor que o pó moído a seco no mesmo período de tempo: $0,7 \mu \mathrm{m}$ contra $0,9 \mu \mathrm{m}$. Pode-se dizer que tal diferença não foi significativa, considerando o fato das curvas de distribuição de tamanho de partículas serem muito próximas.

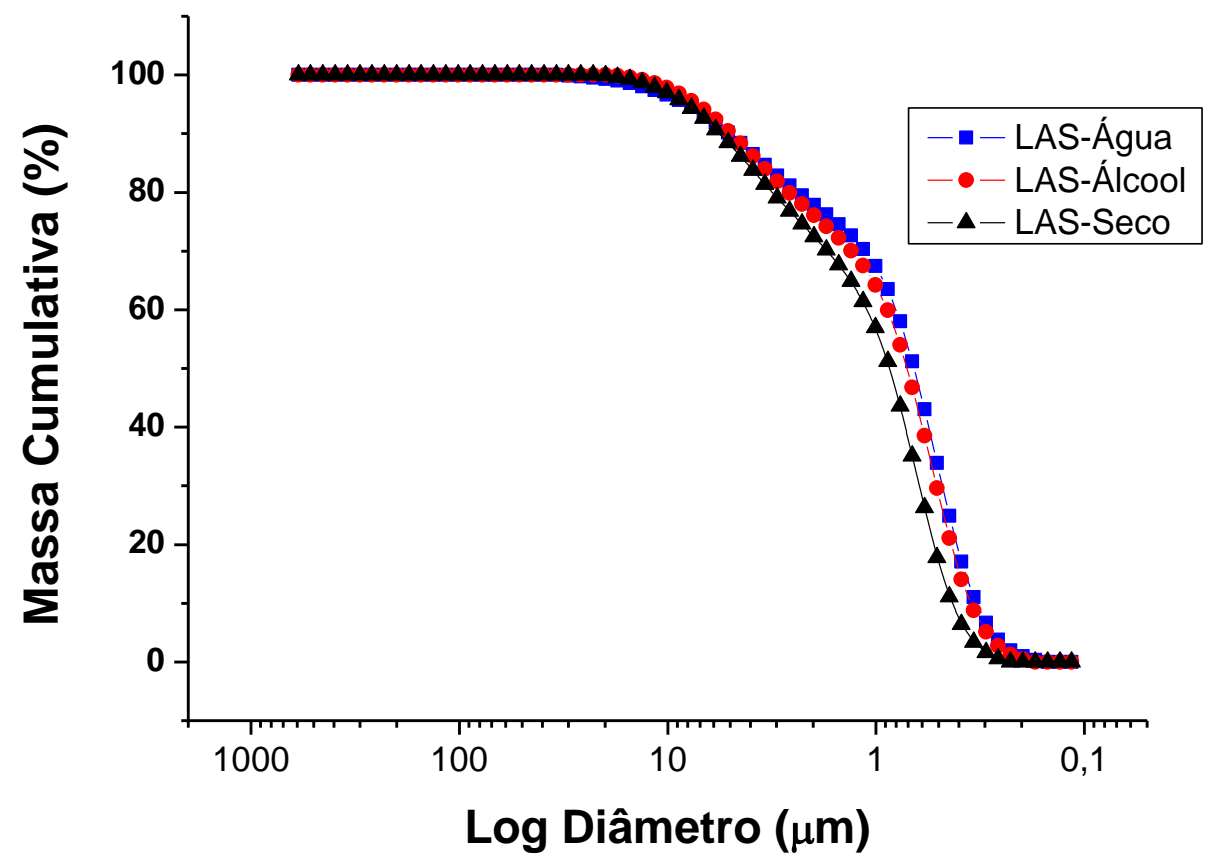

Figura 7: Distribuição de tamanho de partículas do vidro LAS moído em diferentes condições em moinho planetário por 200 minutos. Relação volume de vidro/líquido igual a 0,75 .

A partir dos pós do vidro LAS obtidos por diferentes condições de moagem foram confeccionadas pastilhas via prensagem uniaxial e estas amostras foram sinterizadas a $1100^{\circ} \mathrm{C}$ usando uma taxa de aquecimento de $30^{\circ} \mathrm{C} / \mathrm{min}$. A Tabela 3 mostra a fração de poros residual determinada para as amostras sinterizadas a partir de diferentes granulometrias. Nota-se que não houve diferença significativa entre a fração de poros das vitrocerâmicas obtidas a partir do vidro moído a seco por $60 \mathrm{~min}$ e $90 \mathrm{~min}$, sendo estes os menores valores alcançados para a fração de poros (4,8 $\pm 0,2$ e 4,7 $\pm 0,1$ respectivamente). Por outro lado, considerando apenas a moagem a seco, o aumento do tempo de moagem levou ao aumento da fração de poros, sendo obtida uma fração de poros de $6,0 \pm 0,4$ para a vitrocerâmica obtida a partir do pó moído por 200 min. Isto aponta o aumento de $\mathrm{N}_{\mathrm{s}}$ com o tempo de moagem e a consequente cristalização precoce da superfície das partículas, impedindo a sinterização por fluxo viscoso. Como a sinterização e a cristalização são processos concorrentes em vidros, uma vez que a obtenção de partículas finas favorece a sinterização devido à alta área superficial, também pode ocorrer o aumento de $\mathrm{N}_{\mathrm{s}}$ e a cristalização precoce da superfície impedir a sinterização.

Pela Tabela 3, também pode ser visto o efeito da moagem a úmido na sinterização do vidro LAS. Considerando o tempo de moagem de $200 \mathrm{~min}$, nota-se que não houve diferença significativa entre a fração de poros das vitrocerâmicas obtidas a partir dos pós moídos a seco e em água, sendo estes valores $6,0 \pm 0,4$ e $5,8 \pm 0,9$. Isto indica que o dano mecânico na superfície das partículas causado pela moagem a seco é similar àquele causado pela moagem a úmido na presença de água. No entanto, para a vitrocerâmica obtida a partir do pó moído em álcool isopropílico a fração de poros medida foi de $20 \pm 1$, sendo este valor muito elevado, indicando um altíssimo valor de $\mathrm{N}_{\mathrm{s}}$ para este pó. 
Tabela 3: Fração de poros das vitrocerâmicas LAS obtidas a partir de diferentes condições de moagem e granulometrias.

\begin{tabular}{c|c|c}
\hline CONDIÇÕES DE MOAGEM & TAMANHO MÉDIO DE PARTÍCULA $(\boldsymbol{\mu m})$ & FRAÇÃO DE POROS (\%) \\
\hline Vidro moído por 60 minutos & 4,88 & $4,8 \pm 0,2$ \\
\hline Vidro moído por 90 minutos & 3,27 & $4,7 \pm 0,1$ \\
\hline Vidro moído por 200 minutos & 0,9 & $6,0 \pm 0,4$ \\
\hline Vidro moído por 200 minutos em água & 0,7 & $5,8 \pm 0,9$ \\
\hline Vidro moído por 200 minutos em álcool & 0,7 & $20 \pm 1$ \\
\hline
\end{tabular}

\section{DISCUSSÃO}

Minimizar o tempo de moagem e atingir o menor tamanho possível de partículas, simultaneamente, é fundamental para maximizar a densificação de pós vítreos durante o processo de sinterização com cristalização concorrente. Isto porque o caminho para favorecer a sinterização via fluxo viscoso é evitar a cristalização precoce da superfície das partículas. Os modelos propostos para a sinterização de vidros apontam os principais parâmetros que afetam este processo e as condições que o favorece, estes são: tensão superficial (alta), taxa de crescimento de cristais (baixa), densidade inicial do compacto (alta), tamanho de partículas (pequeno) e $\mathrm{N}_{\mathrm{s}}$ (pequeno) [12,13,14]. Dentre estes parâmetros, a tensão superficial e taxa de crescimento de cristais dependem da composição do vidro, a densidade inicial do compacto depende das condições de processamento do pó (prensagem), mas o tamanho de partículas e $\mathrm{N}_{\mathrm{s}}$ são diretamente afetados pelo processo de moagem e podem ser controlados. Embora $\mathrm{N}_{\mathrm{s}}$ seja um parâmetro difícil de ser determinado experimentalmente, principalmente para partículas muito finas, Müeller [3,5,8] demonstrou que menores valores de $\mathrm{N}_{\mathrm{s}}$ estão associados a curtos tempos de moagem, pois isto leva a um menor dano mecânico na superfície das partículas e reduz o número de imperfeições (riscos, trincas, etc.) que podem induzir a cristalização precoce da superfície barrando a sinterização via fluxo viscoso. Neste trabalho, a otimização dos parâmetros de moagem de alta energia possibilitou reduzir consideravelmente o tempo de moagem, quando comparado ao tempo de moagem em moinho de jarros convencional, como mostrado nas Figuras 3 e 4 .

Ao avaliar a sinterização de um vidro LAS para os pós obtidos nas condições otimizadas de moagem, verificou-se que os pós obtidos por tempos mais curtos de moagem apresentaram maior densificação (Tabela 3), embora estes pós apresentassem uma distribuição de tamanho de partículas mais grosseira (Figura 5). Isto mostra a forte influência do parâmetro $\mathrm{N}_{\mathrm{s}}$ na sinterização de vidros. Embora, intuitivamente, se espere que partículas mais finas apresentem maior sinterabilidade, pós finos que apresentem elevado valor de $\mathrm{N}_{\mathrm{s}}$ não irão resultar na alta densificação do compacto [15]. Um resultado semelhante foi verificado por Mohammadi et al. [16] onde o aumento do tamanho de partículas favoreceu a sinterização de vitrocerâmicas de wollastonita e pós de granulometria mais grosseira $(16 \mu \mathrm{m})$ apresentaram maior densificação. Quanto a moagem a úmido, o uso de álcool isopropílico foi extremamente danoso para a sinterização do vidro LAS, levando a uma fração de poros de $20 \%$ (Tabela 3). Isto indica um maior $\mathrm{N}_{\mathrm{s}}$ para este pó. Durante a moagem, ocorre o aquecimento do jarro devido à alta energia cinética dos meios de moagem, isto acarretou a volatilização parcial do álcool isopropílico, deixando a mistura vidro/álcool com uma viscosidade elevada, causando uma maior contaminação do pó, que apresentou uma coloração cinza. Desta forma, o maior dano mecânico sofrido pelas partículas de vidro e as partículas contaminantes provenientes do desgaste dos meios de moagem são responsáveis pelo maior Ns apresentado por este pó, impedindo sua sinterização por fluxo viscoso e resultando em uma alta fração de poros.

\section{CONCLUSÕES}

A otimização do processo de moagem de alto impacto, utilizando um moinho planetário, possibilitou a obtenção de pós vítreos utilizando-se tempos de moagem abaixo de 200 minutos, o que possui forte impacto sobre a sinterização de vidros. O vidro de janela serviu como um bom padrão para este estudo, uma vez que levou a curvas de distribuição de tamanho de partículas muito próximas daquelas obtidas para o vidro LAS. As moagens realizadas com tempos de 60 min e 90 min apresentaram um diâmetro médio de partículas de cerca de $5 \mu \mathrm{m}$ e $3 \mu \mathrm{m}$ respectivamente, os pós obtidos apresentaram fração de poros abaixo de $5 \%$ após a sinterização. Moagens com maiores tempos (ex: 200 minutos) levaram a pós com baixíssimo diâmetro médio $(0,70-0,80 \mu \mathrm{m})$, contudo estes pós não deram bons resultados sob o ponto de vista da sinterização. Nossos estudos demonstraram que, para favorecer a sinterização de pós vítreos que apresentam alta tendência à cris- 
talização superficial, é recomendável a utilização da moagem de alta energia a seco e por tempos de moagem inferiores a $90 \mathrm{~min}$.

\section{AGRADECIMENTOS}

Os autores agradecem ao suporte financeiro da Fundação de Amparo à Pesquisa do Estado de São Paulo FAPESP - processo 07/00028-1 e ao Conselho Nacional de Desenvolvimento Científico e Tecnológico CNPq processo 104429/2019-4.

\section{BIBLIOGRAFIA}

[1] PANNHORST, W., "Glass ceramics: state-of-the-art”, Journal of Non-Crystalline Solids, v. 219, pp. 198204, 1997.

[2] PRADO, M. O., ZANOTTO, E. D., "Glass sintering with concurrent crystallization", Comptes Rendus Chimie, v. 5, n. 11, pp. 773-786, 2002.

[3] MÜLLER, R., ZANOTTO, E. D., FOKIN, V. M., "Surface crystallization of silicate glasses: nucleation sites and kinetics", Journal of Non-Crystalline Solids, v. 274, n. 1-3, pp. 208-231, 2000.

[4] Gutzow, I., et al., "The kinetics of surface induced sinter crystallization and the formation of glassceramic materials", Journal of Materials Science, v. 33, pp.5265 - 5273, 1998.

[5] MÜLLER, R., REINSCH, S., GABER M., "Sinterability of glass powder", GlastechnischeBerichte-Glass Science and Technology, v. 73 C1, pp. 205-212, 2000.

[6] SOARES, V. O., PEITL, O., ZANOTTO, E. D., "New sintered Li2O-Al2O3-SiO2 ultra-low expansion glass-ceramic", Journal of the American Ceramic Society, v. 96, n. 4, pp. 1143-1149, 2013.

[7] ROGACHEV, A. S., et al., "Experimental investigation of milling regimes in planetary ball mill and their influence on structure and reactivity of gasless powder exothermic mixtures", Powder Technology, v. 274, pp. 44-52, 2015.

[8] MÜLLER, R, REINSCH, S., "Viscous Phase Silicate Processing”. In: "Processing Approaches for Ceramics and Composites", eds., Bansal, N., Boccaccini, A. R., John Wiley \& Sons, Inc., Hoboken, NJ, pp. 75144,2012

[9] FEST, S., REINSCH, S., MUELLER, R., "Milling, sintering and crystallization of 11BaO-25CaO64SiO2 glass powder", International Journal of Applied Glass Science, v. 5, n. 3, pp. 236-247, 2014.

[10] TOMASI, R., et al., "Characterization of high-energy milled alumina powders", Cerâmica, v. 44, n. 289, pp. 166-170, 1998.

[11] GHAFFARI, S., et al., "The effects of high-energy ball milling on the synthesis, sintering and microwave dielectric properties of Li2TiO3ceramics", Journal of Materials Science: Materials in Electronics, v. 29, n. 13, pp. 10933-10941, 2018.

[12] PRADO, M. O., FREDERICCI, C., ZANOTTO, E. D., "Isothermal sintering with concurrent crystallization of polydispersed soda-lime-silica glass beads", Journal of Non-Crystalline Solids, v. 331, n. 1-3, pp. 145-156, 2003.

[13] PRADO, M. O., FREDERICCI, C., ZANOTTO, E. D., "Non-isothermal sintering with concurrent crystallization of polydispersed soda-lime-silica glass beads", Journal of Non-Crystalline Solids, v. 331, n. 1-3, pp. 157-167, 2003.

[14] SOARES, V. O, et al., "Non-isothermal sinter-crystallization of jagged Li2O-Al2O3-SiO2 glass and simulation using a modified formof the Clusters model", Journal of Non-Crystalline Solids, v. 358, n. 23, pp. 3234-3242, 2012.

[15] PRADO, M. O., FREDERICCI, C., ZANOTTO, E. D., "Glass sintering with concurrent crystallization. Part II. Non-isothermal sintering of jagged polydispersed particles", Physics and Chemistry of Glasses, v. 43, n. 5, pp. 215-223, 2002.

[16] MOHAMMADI, M., ALIZADEH, P., ATLASBAF, Z., "Effect of frit size on sintering, crystallization and electrical properties of wollastonite glass-ceramics", Journal of Non-Crystalline Solids, n. 357, pp. 150$156,2011$. 


\section{ORCID}

Viviane Oliveira Soares

https://orcid.org/0000-0002-0205-6118

Gustavo Rocha de Paula

https://orcid.org/0000-0001-9258-5779

Mariana de Oliveira Carlos Villas Boas

Roney Peterson Pereira

https://orcid.org/0000-0002-6083-8281

https://orcid.org/0000-0002-9991-6240 